\title{
LA ENSEÑANZA DE OFICIOS MECÁNICOS EN NUEVA GRANADA EN VÍSPERAS DE LA INDEPENDENCIA
}

\author{
Jesús Paniagua Pérez \\ UNIVERSIDAD DE LEÓN
}

\section{RESUMEN}

Los ilustrados españoles y neogranadinos habían apreciado la falta de profesionales de los diferentes oficios. Quisieron también acabar con la lacra de los vagos y gentes sin especializar, por lo que se inició toda una política de educación antes y después de la independencia para elevar el nivel de la formación profesional con la fundación de escuelas, academias, sociedades, etc. donde se formaran los artesanos con los que se debía afrontar el futuro. Los gremios, en este panorama, jugaron un importante papel como instituciones reformadas o llamadas a extinguir.

PALABRAS CLAVE: Enseñanza, Oficios, Nueva Granada, Siglos XVIII-XIX.

\section{ABSTRACT}

The Spaniards and Newgranadins of the Enlightenment recognized the lack of trained professionals in the various crafts. They all wanted to end the affliction of vagabonds and people without training, and so initiated both pre- and post-independence educational policies to elevate the level of professional training by establishing schools, academies, societies, etc., where future craftsmen would be trained. Guilds, in this panorama, played an important role as institutions either to be reformed or targeted for extinction.

KEY WORDS: Education, Crafts, Nueva Granada. $18^{\text {th }}-19^{\text {th }}$ centuries. 


\section{INTRODUCCIÓN}

Si en algo se caracterizó la enseñanza durante la Ilustración fue en la aplicación de métodos de observación, por medio de los cuales se enfrentaban a la realidad, que trataban de captar para modificarla, si ello era preciso. Esa observación, con frecuencia hizo que muchos autores se centraran en su propia realidad, que a la postre era lo que conocían y sobre lo que podían actuar; por tanto, a muchos de ellos más que América en su conjunto les interesaba el espacio en el que se movían sus intereses, como queda patente en los aspectos educativos en torno al desarrollo de los oficios mecánicos. Incluso, las grandes proposiciones que hicieron algunos teóricos, interesaron en la medida en que se adecuaban a un determinado espacio. La concepción de América como un todo quedó para los grandes discursos y de manera muy especial para los europeos, incapaces de concebir desde la lejanía la variedad y la singularidad e, incluso, de reconocer las capacidades de los americanos, manteniéndose en una línea que ya había propiciado Adam Smith, que al mencionar a la Nueva Granada, la consideraba como un lugar de salvajes en que las artes y la industria habían florecido solamente tras la presencia española ${ }^{1}$; una visión no muy lejana era la que planteaba el último Kant, que consideraba que, en lo espiritual, los americanos y los negros se hallaban por debajo de las demás razas, sobre todo los primeros.

Los ilustrados españoles y americanos habían apreciado la falta de profesionales en los trabajos mecánicos y su importancia para el desarrollo de las colonias, bien en sí mismas o como abastecedoras de la metrópoli. El avance industrial de Inglaterra y el auge de otros países europeos, así como de Estados Unidos, se convirtió en un punto de referencia para las viejas posesiones españolas. Por un lado, los que abogaban por un desarrollo de España en función de sus dominios ultramarinos; por otro, quienes ya tenían especial interés en promocionar sus territorios de origen y elevarlos a la categoría de entes productores y consumidores, que pudiesen competir en los mercados internacionales. En ambos casos, los ilustrados tenían claro que se necesitaba de un proceso educativo adecuado a las nuevas tendencias, como fuente del progreso y de la felicidad de los pueblos.

Tal educación, en lo referente a los oficios mecánicos, se plantearía por medio de diversas soluciones. Hubo quienes prefirieron el mantenimiento tradicional de los gremios o de los talleres artesanales, aunque con profundas reformas, tratando de evitar su autonomía respecto del poder central en un afán de control, que caracterizaría al siglo XVIII como ejemplo del despotismo ilustrado; otros optaban por una enseñanza reglada en colegios y centros creados al efecto; y no faltaron tampoco las fórmulas mixtas. Lo cierto es que la Nueva Granada se iba a convertir en un campo de experimentación educativo-profesional, como pocos lugares lo fueron en la América española, siempre con intentos de una normativización emanada de las autoridades y respondiendo al centralismo de la Corona; de ahí que en muchos casos sean los propios virreyes y los altos funcionarios los artífices de las reformas.

Al margen de los estudios actuales, abundantes sobre todo en lo referido a la época postindependentista, la propia prensa de la época fue todo un reflejo del interés por po-

1 SMITH, Adam: La riqueza de las naciones, México, Fondo de Cultura Económica, 2006, L. I, c. II, sec. 2. 
tenciar los trabajos mecánicos, de manera muy especial el Papel Periódico, el Correo Curioso y el Semanario del Nuevo Reino de Granada. En cuanto a bibliografía son muchas las obras que existen sobre la ilustración neogranadina, tales como las de Germán Colmenares, José María Vergara, Jaime Jaramillo Uribe, Renán Silva, Peralta Agudelo, Santiago Castro, Juan Manuel Pacheco y un largo etcétera en que podemos destacar los volúmenes que sobre esta temática ha coordinado la Dra. Diana Soto Arango, así como estudios de vida y obras de ilustrados como Mutis, Nariño, Caldas, Escandón, etc.

\section{LA SOCIEDAD NEOGRANADINA PREINDEPENDENTISTA Y LA ENSEÑNAZA DE LOS OFICIOS MECÁNICOS}

Uno de los problemas planteado por los ilustrados fue el de la utilidad, al que hacía mención el primer número del Papel periódico, que se iniciaba con la frase de Tito Livio, Communis utilitas societatis maximum est ${ }^{2}$. La tan exaltada utilidad obligaba a afrontar profundos cambios en la desarrollo de la enseñanza de los trabajos manuales, pero entraba en contradicción con un viejo problema, como lo era la tradicional consideración de la ociosidad como un mal que aquejaba tanto a la Nueva Granada, como a España y sus demás posesiones; aunque aquello que tanto se achacó al mundo hispánico no había sido ajeno a otras potencias ${ }^{3}$, si bien se seguía insistiendo en ello como un fenómeno español. Antonio de Ulloa, en esa línea, había denunciado que solo en los lugares poseídos por los españoles se despreciaban los oficios mecánicos, contraponiéndolo a Nueva Inglaterra, donde eran los europeos los que los practicaban, con lo que se evitaba la presencia de gente vagabunda y ociosa ${ }^{4}$. En Nueva Granada denuncias parecidas fueron frecuentes, como la de Moreno y Escandón, en 1772, al mencionar la desidia, el abandono y la flojedad de sus habitantes, siempre contentos con su ocio ${ }^{5}$.

Los intentos de solución pasaron esencialmente por el fenómeno de la dignificación del trabajo, como ya lo habían hecho muchos arbitristas del siglo XVII. Pero no fue hasta el siglo XVIII cuando se materializó la pretensión efectiva entre algunos ilustrados, que consideraron el trabajo manual no solo como algo digno, sino también como un elemento civilizador, pues la formación de trabajadores implicaba, además de aspectos técnicos, la promoción de hombres virtuosos y de buena conducta, útiles a la monarquía. Como consecuencia, la enseñanza de los oficios, controlada desde el poder y teóricamente liberada de su condición de vileza, implicaba una consideración pública, aspectos por los que todavía abogaba el Correo Curioso, en 1801.

Oficialmente el proceso de dignificación de los trabajos mecánicos se materializó por la real provisión de 18 de marzo de 1783, en que declaraban honrados en España y sus posesiones todos los oficios, sin que inhabilitasen para la consideración de hidalguía ni para ocupar empleos públicos municipales ${ }^{6}$. No fue hasta el 4 de marzo de 1805

\footnotetext{
2 Papel periódico de la ciudad de Santa Fe de Bogotá, no 1 (9 de febrero de 1791).

3 PANIAGUA PÉREZ, Jesús: Trabajar en las Indias. Los trabajos mecánicos 1492-1850, Salamanca, Lobo Sapiens, 2010, pp. 254-266.

4 ULlOA, Antonio de: Noticias Americanas: entretenimientos phisicos-históricos, Madrid, Manuel de Mena, 1772, pp. 348-349.

5 MORENO Y ESCANDÓN, Francisco José: "Estado del virreinato de Santafé, Nuevo Reino de Granada", Anales de la Universidad Nacional de los Estados Unidos de Colombia 4-19 (1870), p. 81.

6 Novísima Recopilación de las Leyes de España, L. VIII, T. XXIII, ley 8.
} 
cuando se mandó aplicar en América, aunque previamente fueron muchas las voces que se levantaron a favor de aquella dignificación. José de Caldas, como padre general de menores de Popayán, presentó un informe al gobernador Diego Antonio Nieto, en 1793, sobre la ociosidad de la juventud payanesa, en que mencionaba los talleres vacíos y abogaba por obligar a los jóvenes a colocarse con un maestro de un oficio, sin distinguir entre nobles y plebeyos ${ }^{7}$. El Correo Curioso expresaba aquella dignificación en frases como "más vil es el noble que pasa sus días en una vergonzosa pereza, que el artesano que profesa un oficio, por más humilde que sea"; como también "El país en que no florecen las Artes no puede por menos que estar lleno de mendigos y de gente ociosa" 8 . De esta forma se pretendía acabar con la tradicional ociosidad, que daba preferencia a una vida de miseria antes que dedicarse a trabajos manuales, sinónimo hasta entonces de deshonra9.

Consecuencia de la ociosidad era la infelicidad de los pueblos, que debía atajarse por medio de la enseñanza, que conduciría al desarrollo y a la felicidad privada y pública. Quien en la Nueva Granada mejor vinculó estos conceptos fue Caldas, como se aprecia en sus artículos del Semanario de la Nueva Granada; es más, establecería una relación directa entre infelicidad e ignorancia. Pero el asunto se hallaba muy generalizado entre determinados sectores. El gobernador de Cartagena, Joaquín Cañaberal y Ponce (17891796), promulgó un reglamento para "la felicidad del pueblo" y "excusando el ocio", en el que establecía las reglas a las que se debían someterse los artesanos, tales como la prohibición de los juegos de truco, la obligación de denunciar a quienes no acudían a su trabajo sin causa y, sobre todo, lo que se recogía en el punto 21, por el que los niños, a partir de los nueve años, debían aprender algún oficio según su clase y esfera, de lo contrario se consideraría culpables a los padres o tutores ${ }^{10}$. Otro ejemplo nos lo ofreció Juan Antonio Mon y Velarde, defensor de la enseñanza de oficios mecánicos, pues al hacer su visita a la jurisdicción de Antioquia, manifestaba que el ocio era la fuente y origen de donde dimanaban los delitos ${ }^{11}$.

Frente a los aspectos teóricos, las medidas que se tomaron adolecieron de defectos y/o de obstáculos insalvables en la época. Era difícil incardinar en el proceso de aprendizaje y ejercicio de oficios mecánicos a todos los habitantes, pues los sectores sociales más poderosos difícilmente podían aceptar aquello, ya que las soluciones pasaban por proteger a los más desheredados de la sociedad. En el mencionado caso de Antioquia, Mon y Velarde puso a los niños vagabundos y sin padres a las órdenes de maestros de oficios $^{12}$. Algo parecido se planteaba en las Ordenanzas de Cañaberal y Ponce para Cartagena, en $1789^{13}$. En Cali, en el censo de 1797, predominaban en los oficios los

7 HERNÁNDEZ ALBA, Guillermo: Documentos para la Historia de la Educación en Colombia V, Bogotá, Nelly, 1983, pp. 333 y ss.

8 Correo Curioso de 10 de noviembre de 1801.

9 KONETZKE, Richard: Colección de documentos para la Historia de la formación social de Hispanoamérica 1493-1810, III, Madrid, CSIC, 1953, p. 366.

10 MORA DE TOVAR, Gilma: "El deber de vivir ordenadamente para obedecer al Rey", Anuario colombiano de historia social y de la cultura 20 (1992), pp. 111-131. Hace alusión a los oficios mecánicos en los capítulos 18-30.

11 MON Y VELARDE, Juan Antonio: Sucinta relación de lo ejecutado en la visita de Antioquia por el oidor..., Bogotá, Banco de la República, 1954, punto nº 82. (ed. de Emilio Robledo).

12 Ibídem, puntos $\mathrm{n}^{\mathrm{o}} 113$ y 114 .

13 MORA DE TOVAR, Gilma: op. cit., capítulo 22. 
mestizos y los pardos ${ }^{14}$, situación que aún era más exagerada en Cartagena, donde los artesanos mulatos incluso disponían de esclavos ${ }^{15}$. Joaquín de Finestrad abogaría porque se recogiesen los zánganos de la república para obligarlos a mantenerse con el trabajo de sus manos, aprendiendo oficios útiles ${ }^{16}$. Si a ello añadimos los intentos de promoción del trabajo con los asuntos de beneficencia las cosas se hacían más complicadas para que los sectores privilegiados aceptasen los oficios mecánicos como algo que no les deshonraba. El virrey Ezpeleta (1789-1797) pretendió crear una casa pública de beneficencia donde se recogieran los hombres pobres e impedidos y tuviesen trabajo para ganarse su sustento y donde se ejercitasen y aprendiesen oficios e industrias, especialmente de las que no había en el país ${ }^{17}$. En la misma ciudad de Santafé se pedía que a los niños de la Casa de Expósitos se les pusiese con maestros para aprender oficios; de hecho, en las constituciones de este centro, en 1777, se mandaba tener un librito con los materiales para las manufacturas y del producto de estas para fomentar los trabajos de más ventaja (capítulo IV, título 3).

Aún los propios defensores de los trabajos mecánicos acababan por caer en la trampa de considerar estos como propios de sectores desfavorecidos de la sociedad. Así, en el plan de la Universidad propuesta por Caballero y Góngora para Santafé, en 1787, se decía que el director de estudios usaría de medios suaves pero eficaces para que los hijos de artesanos, labradores y gentes miserables de dentro y fuera de la capital se dedicasen al estudio de artes industriales "si no tienen proporción para seguir otra carrera"18.

Amén del interés por revalorizar los oficios mecánicos, estos, en la mente de los teóricos, se mantuvieron siempre en un segundo plano respecto del sector primario, pues predominaban las ideas fisiócratas, que consideraban la agricultura como primordial y la industria como un complemento necesario. Finestrad recurrió al ejemplo de la producción textil de Socorro, donde la dedicación agrícola permitió que se implementaran las labores de tejidos, "fecundísimo ramo de la actual industria popular, capaz por sí sola de llenar de bienes y felicidades a sus habitantes con notable preferencia entre las demás provincias del Reino" ${ }^{19}$. Era obvio, además, que el desarrollo agrícola americano se consideró como fundamental, puesto que existía la creencia de que las Indias debían ser ante todo productoras de materias primas y consumidoras de manufacturas metropolitanas $^{20}$; de ahí que incluso se hicieran intentos por favorecer nuevos cultivos como la producción de cochinilla en tiempos del virrey Flórez, que acabó por fracasar ${ }^{21}$.

14 LLANO R., Gonzalo Federico del: "La presencia de los artesanos en el contexto de la historia de la ciudad de Santiago de Cali, siglos XVI a XVIII”, en Revista Hispanoamericana No 25 (1999), pp. 73 y ss.

15 MÚNERA, Alfonso: "El Caribe colombiano en la república andina: identidad y autonomía política en el siglo XIX”, Boletín Cultural y Bibliográfico n 41 (1996).

16 FINESTRAD, Joaquín de: El vasallo instruido en el estado del Nuevo Reino de Granada y en sus respectivas obligaciones, Bogotá, Universidad Nacional de Colombia, 2001, p. 346.

17 GROOT, J.M.: Historia eclesiástica y civil de Nueva Granada escrita sobre documentos auténticos II, Bogotá, Medardo Rivas, 1869, p. 76. HENAO, J.M. y ARRUBLA, G.: Historia de Colombia para la enseñanza secundaria I, Bogotá, Librería Colombiana, 1920, p. 238.

18 Reproducido en HERNÁNDEZ DE ALBA, Guillermo: "Contribución al estudio del desarrollo de las Humanidades en Colombia. El plan de estudios del Arzobispo-Virrey”, Thesaurus 2 (1946), pp. 293-316.

19 FINESTRAD: op. cit., p. 151.

20 RODRÍGUEZ DE CAMPOMANES, Pedro: Discurso sobre el fomento de la industria popular, Madrid, Antonio de Sancha, 1774.

21 CALDAS, Francisco José de (ed.): Semanario de la Nueva Granada..., p. 534. 
También fue calando la idea de la libertad de trabajo, ya defendida por Adam Smith, que había considerado la fuerza y destreza de las manos como el principal patrimonio de los pobres; por tanto, nadie podría ponerles trabas en el desarrollo de sus habilidades y, obviamente, los gremios eran un problema en ese sentido. Frente al corporativismo laboral se iban imponiendo, pues, el individualismo patrocinado en su día por Hobbes y Locke. Así, los diputados americanos reclamaron en las Cortes de Cádiz, donde se leyó una representación el 16 de diciembre de 1810, que los pueblos de América pudieran gozar sin restricciones de la dedicación a los oficios mecánicos.

En todo aquel cúmulo de pensamientos más o menos novedosos y lo que la realidad del momento imponía, el fin del periodo español en América en general y en la Nueva Granada en particular se caracterizó por una triple postura ante la enseñanza de los trabajos mecánicos. Por un lado, quienes fueron favorables a conservar los gremios y su tradicional sistema de enseñanza de aprendices-oficiales y maestros, en un ascenso que teóricamente se hacía por medio de exámenes, con los pagos pertinentes y con una tendencia en muchos lugares a la prevaricación; por otro lado, quienes, siguiendo las teorías de algunos ilustrados españoles, como Campomanes y Jovellanos, abogaron por la extinción de los gremios o por su reforma profunda; aunque el tema fue abordado también por otros autores como Feijoo, Cadalso, Foronda, Hervás y Panduro, Flores Estrada, etc. ${ }^{22}$. Por último, los intentos de creación de centros docentes y/o benéficos donde se llevara a cabo algún tipo de aprendizaje.

\section{MANTENIMIENTO DE LOS GREMIOS}

La organización gremial en la América española no había sido un fenómeno generalizado en sentido estricto. Solo algunas de las grandes ciudades, como México, Lima o Quito habían gozado de un sistema gremial más o menos amplio, organizado y reconocido oficialmente. Por lo general, aunque los trabajos mecánicos habían tenido una cierta reglamentación, la mayor parte de las ciudades no tuvieron gremios o los crearon ya muy tardíamente, como en el caso de las de la Nueva Granada. Aún así, casi todas las ciudades mantuvieron un sistema que se acercaba al gremialismo, en la medida en que en los oficios mantenían la clásica división aprendiz-oficial-maestro. Como, al no haber gremios no solía haber ordenanzas, los cabildos intervenían con mayor o menor éxito en determinados aspectos organizativos y de cobros de impuestos, especialmente los aranceles; se protegía a los artesanos; se les imponía una ubicación más o menos respetada, etc., lo que dio lugar a lo que se ha llamado "paragremialismo"23. También es cierto que la situación había ido degenerando, tanto en el control de la actividad y de los ejercitantes de trabajos mecánicos como en las posibilidades de ascenso, ya que fue frecuente que los maestros, sobre todo en los oficios más rentables y/o de mayor consideración, alimentaran sus redes familiares e impidieran la promoción de otros oficiales y aprendices, para garantizarse además una mano de obra barata.

De todos modos, aunque fue el último cuarto del siglo XVIII cuando se plantearon las mayores reformas en la enseñanza de los oficios, ya hubo algunos precedentes de

22 Un resumen de lo mantenido por estos autores puede verse en PANIAGUA PÉREZ: op. cit., pp. 186 y ss. 23 PANIAGUA PÉREZ, Jesús y TRUHAN, Deborah. L.: Oficios y actividad paragremial en la Real Audiencia de Quito (1557-1730). El corregimiento de Cuenca, León, Universidad de León, 2003. 
denuncia y de transformación en la Nueva Granada. Valgan los ejemplos del presidente de la Audiencia de Santafé, Antonio Manso y Maldonado, que al dejar su cargo en 1731 manifestaba que no había personas suficientes ejercitando oficios, porque la gente era ociosa y aplicada al delito ${ }^{24}$. El virrey Guirior, en 1776, en las instrucciones que dejaba a su sucesor, mencionaba que la prosperidad del estado dependía de la formación de la juventud, entre otras cosas en la industria. Fue precisamente con su sucesor, Manuel Antonio Flórez (1776-1781), con el que se marcó una inflexión en los intentos por las reformas educativas del artesanado. Este virrey fue un verdadero ilustrado, reformador como ninguno, de cuyas actividades se haría eco su sucesor el arzobispo Antonio Caballero y Góngora (1782-1789), defensor de una educación juiciosa ${ }^{25}$.

En las décadas finales del siglo XVIII, cuando el sistema gremial entraba en crisis, en América se optó por una reorganización del mismo, lo que podría parecer anacrónico, cuando en Europa se abogaba por la libertad de trabajo y se tendía a una reorganización de la producción de carácter más industrial, que permitiera una mayor competitividad en los mercados, en que el avance de las ideas liberales y el renacimiento del individualismo se enfrentaban a todo atisbo de corporativismo. De hecho, ya en los momentos finales del Antiguo Régimen, Turgot había afrontado la abolición de los gremios en Francia con los seis edictos de 1775, para así favorecer la libre circulación comercial, aunque sin éxito final, hasta que en 1791 la Ley Chapelier abolió el corporativismo laboral y declaró la libertad de trabajo, que se consagraría con el Código Civil de Napoleón, en 1804. Pero en la América española, la situación no facilitaba la entrada en la modernidad. Su artesanado no estaba preparado para cambios drásticos y se optaba por mejorar lo existente, puesto que era casi imposible eliminar el sistema gremial o sus sucedáneos y hubo que contemporizar con su decadencia y tratar de obtener los mejores resultados posibles, lo que incidía directamente sobre los asuntos de formación. Ahora bien, también se tendía a limitar las prerrogativas de las que se había gozado hasta entonces, en función de un mayor control por los poderes centrales y unos mejores resultados en la formación, que se abordó casi siempre desde lo público.

Donde primero se intentaron las reformas gremiales fue en aquellos oficios relacionados con los metales preciosos, debido al interés de la Corona por controlar la producción y los fraudes y garantizar al fisco unas buenas recaudaciones. Como consecuencia, en Nueva Granada se mandaba poner en práctica, el 12 de octubre de 1776, la famosa real cédula dada para Guatemala ${ }^{26}$, que centraba los problemas educativos en la ordenanza quinta. En ella se abogaba por una formación sólida de los aprendices, incluso en el terreno moral, lo que según el artículo décimo deberían controlar el veedor y los diputados. Pero lo más novedoso estaba en la corrección de la ordenanza tercera, por la cual se permitía abrir talleres a indios, mestizos y mulatos, que hasta entonces tenían limitado su acceso a los oficios agremiados y relacionados con los metales preciosos. A juzgar por lo que sabemos, no debió surtir mucho efecto, pues los plateros españoles consiguieron mantener el control de sus gremios, que hasta entonces habían gozado de

24 HENAO y ARRUBLA, op cit. p. 178.

25 GIRALDO JARAMILLO, Gabriel (ed.): Relaciones de mando de los virreyes de la Nueva Granada. Memorias económicas, Bogotá, Banco de la República, 1954, pp. 98 y ss.

26 Una reproducción de estas Ordenanzas puede verse en PANIAGUA PÉREZ, Jesús y GARZÓN MONTENEGRO, Gloria $\mathrm{M}^{\mathrm{a}}$ : Los gremios de plateros y batihojas en la ciudad de Quito (siglo XVIII), México, UNAM, 2000, pp. 227-234. 
una categoría muy especial entre los trabajos mecánicos; si bien existieron indios, mestizos y mulatos, que ejercieron estas tareas, lo hicieron en función de una permisividad admitida tradicionalmente, pero apartados de la organización reservada a los blancos.

En Nueva Granada, la situación del aprendizaje y desarrollo de los oficios era considerada como catastrófica por casi todos los teóricos y autoridades de la época. El propio virrey Flórez ofrecía una imagen de pobreza, ociosidad y vida licenciosa de los artesanos, que apenas se diferenciaban en su aspecto de los vagabundos. No es de extrañar, por tanto, que a él se deba una de las soluciones más llamativas e importantes que se produjeron en América, como fue la Instrucción General para los Gremios ${ }^{27}$, que, aunque bajo su aval, era producto de los desvelos de Francisco Robledo, que tuvo en cuenta, ante todo, la obra de Campomanes ${ }^{28}$. Después de pasar la censura del fiscal de la Audiencia, el virrey la mando a varios lugares de la Nueva Granada para que se cumpliese, en tanto era aprobada por el Consejo de Indias. La contaduría del mismo, sin embargo, solicitaba que se añadiese a su formulación el cobro de la media anata de los maestros aprobados y de los veedores, como se hacía en Nueva España. El fiscal del Consejo, por otra parte, pedía que diesen su opinión los cabildos de Santafé, Santa Marta, Cartagena y Quito, así como los procuradores generales del común, exponiendo las posibles modificaciones o ampliaciones ${ }^{29}$.

La Instrucción ponía de manifiesto en sus prolegómenos la situación del artesanado neogranadino, falto casi por completo de toda formación, hasta el punto de exponer que en aquellas tierras no había un maestro que fuese capaz de hacer una mediana pieza de su oficio, ni oficial al que se notase su aplicación. Aquellos artífices estaban faltos de reglas, método e instrucción "capaz de solidar una buena enseñanza" ${ }^{30}$. Los aspectos formativos se tocaban de forma especial entre los puntos 5 y 41, aunque luego volvían a repetirse algunos de ellos. Se reconocía que para arreglar los gremios la mayor dificultad que había era la del método, por la carencia de buenos artífices, debiéndose recurrir a los mejores maestros que hubiese y tratando de romper con la tradición que beneficiaba la sucesión de padres a hijos. El maestro decidiría el tiempo de aprendizaje de acuerdo a las cualidades de cada uno. Pero la formación pasaba porque cualquier aprendiz, que debía entrar como tal en torno a los nueve años, debería asistir desde los cinco a la escuela de primeras letras para aprender a leer y a escribir; aunque había algunos oficios que se consideran exentos de tales formalidades como eran los de molinero, tahonero, molendero de chocolate, confitero, pastelero, colchonero y otros semejantes. Igualmente se debían tener en cuenta las aptitudes del alumno, pues había unos oficios que exigían fuerza física y otros ingenios.

La Instrucción, siguiendo la tradición ilustrada y para dar relieve a quienes ejercían un oficio, se ocupaba muy puntualmente del aseo y de la apariencia. Así, los maestros y los padres cuidarían de que cada aprendiz se lavase y peinase a diario y de que sus ropas estuviesen bien cosidas y remendadas. Se conminaba además a que no dejasen usar a los alumnos ni ruana ni gorro; la primera, porque con ella ocultaban el desaseo

27 FAJARDO DE RUEDA, Marta (ed.): “Instrucción general para los gremios, Santafé, 1777”, Ensayos, n 1 (1993-1994), pp. 187-215.

28 RODRÍGUEZ DE CAMPOMANES, Pedro: Discurso sobre la educación popular de los artesanos y su fomento, Madrid, Antonio Sancha, 1775.

29 AGI, Santa Fe 698

30 FAJARDO DE RUEDA, Marta (ed.): op. cit., pp. 190-191. 
$\mathrm{y}$, por tanto, deberían vestir con ropas cortas; lo segundo, para garantizar que llevaban el cabello limpio.

Como futuros hombres de buenas costumbres, no deberían frecuentar chicherías en días de trabajo, porque allí se bebía y se jugaba, lo que no era recomendable para los jóvenes, a los que sus mayores y formadores deberían dar ejemplo. Tampoco se permitía que oficiales y aprendices fuesen a fiestas en los días de trabajo. Incluso en los días feriados se recomendaba que padres y maestros, como alternativa a las diversiones nocivas, les facilitasen otras actividades lúdicas como el juego de pelota, el de bolas, la esgrima etc. o que en los bailes controlasen que se portasen con decencia.

En la educación también había que influir para que se produjese un cambio de mentalidad, convenciendo al aprendiz que solo la ociosidad era deshonrosa, por lo que en la vida familiar se debía promover la transmisión y el gusto por los trabajos mecánicos; incluso se hacía una llamada a la sociedad, aconsejando que tampoco los que ejerciesen otras actividades considerasen a los artesanos hombres de baja esfera.

Los asuntos de formación se volvían a retomar a partir del punto 53, referente a las escuelas de dibujo, en que se recordaba la obra de Campomanes, que consideraba su enseñanza como necesaria para el desarrollo de los oficios ${ }^{31}$. Sin embargo, se reconocía que en Nueva Granada no había quien pudiese enseñarlo, por lo que en la Universidad que entonces se proyectaba se debería crear una cátedra, que funcionara fuera del horario laboral, y a la que asistieran por turnos semanales los aprendices, bajo control de su maestro. En tal cátedra, además de aprender las generalidades sobre la materia, se estudiaría el diseño de las máquinas, los instrumentos y las operaciones de cada oficio; aclarando que dichos diseños se podían hallar en los libros de las Artes. Todo esto se extendía a los aprendices de los hospicios.

Establecía igualmente las reglas de los exámenes, realizadas por los veedores de cada oficio, en que se debía preguntar primero por los instrumentos del mismo, la calidad, peso y medida de las piezas y, al final, los examinadores elegirían una pieza para que el aspirante la ejecutase en la casa de algún veedor. Los derechos de examen, verdadero problema hasta entonces para quienes no disponían de medios, se solucionaban al obligar a que cada maestro fuese reteniendo cierta cantidad a los aprendices y oficiales, que se depositaría en la tesorería del gremio, para el momento en el que se desease la promoción.

Los jóvenes incorregibles que no se aplicasen al estudio exigido en su oficio, después de reprendidos por sus padres o tutores y maestros, se le destinaría al ejército o a las obras públicas; destino que se daba también a los maestros que reincidiesen en su no asistencia al trabajo y después de rebajarles al grado de oficial.

La finalidad de la Instrucción era la de mejorar la situación del artesanado, manteniéndose todavía en el ámbito de lo gremial y aplicando a aquellos territorios el pensamiento transmitido por Campomanes, quien además de las consideraciones más técnicas abogaba también por la conducta intachable, que implicaba que el artesano debía ser obediente, resignado, con amor al trabajo, cuidar de su higiene personal y tener buenas costumbres. Es cierto que ese autor no pensaba especialmente en el desarrollo de los oficios mecánicos en las Indias, a las que consideraba, como otros muchos me-

31 RODRÍGUEZ DE CAMPOMANES, Pedro: Discurso sobre la educación popular..., pp. 97 y ss. 
tropolitanos, productoras de materias primas ${ }^{32}$. Lo cierto es que se buscaba una especie de hombre nuevo en los oficios mecánicos, cuya formación no solo pasaba por la del propio oficio, sino que pretendía ser más integral, en la medida que insistía en la sociabilidad del artesano y en su servicio a los intereses de la Corona.

La Instrucción pretendía acabar con el desorden existente en el ejercicio de los oficios mecánicos, ya que en muchos lugares ni siquiera se había respetado la vieja tradición o, como en Cartagena, ni siquiera se examinaba a los oficiales y aprendices, cosa que sucedía en otras muchas ciudades, incluida la propia capital. Por ello se recogía algo que correspondía a la tradición y que seguía teniendo validez: "los maestros vigilen la calidad de las piezas y de los materiales, junto con el peso, la medida y el número, que garanticen la firmeza y la solidez del producto". Incluso para una adaptación general de los artífices neogranadinos, especialmente los santafereños, se contemplaba la oportunidad de reciclarse con un examen a maestros y oficiales para reconocerles su grado en la nueva coyuntura, habida cuenta de que eran muchos los que no podían probar que había realizado las pruebas tradicionalmente exigidas.

Al mismo tiempo que se intentaba revalorizar a los gremios y adecuarlos a las necesidades de la época, poniendo énfasis en los aspectos educativos, se los supeditaba de una manera férrea a las autoridades superiores, por lo que se les prohibían las reuniones sin permiso explícito de las mismas y con asistencia de un representante del poder.

Lo cierto es que la Instrucción influiría en la reorganización de los gremios y de la formación en muchos lugares de Nueva Granada, incluso en su creación, cuando estos no existían. Así, en Popayán los gremios se organizaron en $1777^{33}$. Mon y Velarde dictaría una Ordenanza relativa a Oficios y artesanos en Antioquia, que fructificaría en 1788. En Cartagena ya hemos hecho alusión a las Ordenanzas de Cañaberal y Ponce, de 1789. Pasto se vería afectada por la organización gremial que se produjo en $1796^{34}$. Fueron, pues, varias las ciudades que, a partir de la Instrucción, comenzaron a intentar el fomento gremial con parámetros de modernidad.

$\mathrm{El}$ problema era mantener en el camino correcto a aquellas corporaciones, que parece que difícilmente cumplieron con lo establecido para su potenciación y modernización, dejando en las décadas siguientes una idea de fracaso. En 1791 se describían las construcciones de Bogotá como un ejemplo de la descomposición social en que "parece que la ignorancia, el mal gusto y la bajeza de ánimo se congregaron a ser los directores de ese monumento a la ignominia"35. Los vecinos de Antioquia, al acabar el siglo, manifestaban que no se veían artesanos, tan útiles como necesarios al estado ${ }^{36}$. En 1801 Caldas escribía en el Correo curioso que "admira ver las mejores maderas en manos de ignorantes... hallándose en igual grado pintura, platería, herrería y demás oficios" ${ }^{37}$. En la ciudad de Antioquia, en 1807, al hablar de algunos oficios, y en concreto de los sas-

32 RODRÍGUEZ DE CAMPOMANES, Pedro: Discurso sobre el fomento de la industria..., p. CXLV. 33 ARAGÓN, Arcesio: Fastos payaneses (1536-1936), I, Bogotá, Imprenta Nacional, 1939, p. 40.

34 Véase DUQUE, María Fernanda: "Legislación gremial y prácticas gremiales: Los artesanos de Pasto (1796 - 1850)", Historia Crítica, no 25 (2003), p. 117.

35 Papel Periódico de la ciudad de Santafé de Bogota $\mathrm{N}^{\mathrm{o}} 11$ (22 de abril de 1791).

36 GUTIÉRREZ DE PINEDA, Vitoria: La familia en Colombia: trasfondo histórico, Medellín, Universidad de Antioquia, 1997, p. 358.

37 Correo Curioso, $\mathrm{n}^{\circ} 40$ (17 de noviembre de 1801). 
tres, se decía de los 33 existentes, 10 de ellos se consideraban vagos e inútiles ${ }^{38}$. Cuando en 1809 se hizo un plan de economía para el istmo de Panamá por Salvador Bernabeu de Reugart, su artículo cuarto trataba sobre la industria popular y los artesanos, y se reconocía que carecían de educación y policía ${ }^{39}$. En Popayán, en mayo de 1819, y todavía a nombre de la Corona, se intentaba regularizar el funcionamiento de talleres mediante un censo y un examen de las destrezas de los artífices ${ }^{40}$, lo que indica que, aunque ya hubiese gremios, muchos de sus miembros carecían de la capacidad necesaria para desarrollar un oficio ${ }^{41}$. En el mencionado Correo curioso, se hacían una pregunta sobre aquella situación, y su respuesta era clara: “...apenas se conocen, sin tener otros que las que posee cualquier pueblo miserable, como son los malos pintores, y peores albañiles, carpinteros y herreros" ${ }^{42}$. John Steuart nos resume respecto de Santafé el panorama que había al finalizar el periodo español en cuanto a la calidad de las manufacturas, pues define la compraventa de las mismas como un mercado para cacharros $^{43}$.

Es decir, la Instrucción de Flórez no debió causar, ni mucho menos, los efectos apetecidos en un artesanado caracterizado por su ignorancia y viciado por la degeneración en la que habían ido cayendo las antiguas tradiciones. El mejor ejemplo de ello es que el 26 de julio de 1789 Manuel Díaz de Hoyos entregaba al fiscal el Reglamento de los gremios de la plebe para moralizarlos ${ }^{44}$, en que hablaba de gentes sin sujeción, como no la tuvieron tampoco sus padres y abuelos. De nuevo se insistía, como era tradicional, en la dedicación a los trabajos mecánicos de huérfanos y pobres. Este reglamento presentaba dos aspectos contradictorios en lo educativo. Por un lado, había un verdadero interés por la moralidad y las buenas costumbres, pues se hizo para evitar desórdenes y vicios y acabar con vagos y delincuentes; por otro, presentaba un aspecto muy conservador, pues a los maestros y a los jueces de cada oficio se les extendía su poder y control, incluso se les involucró como denunciantes de los escándalos y desórdenes de sus oficiales. Precisamente esos maestros y jueces debían seguir cuidando de la calidad de las obras, que deberían imitar las de Europa o las que hacían los artesanos del Viejo Continente asentados allí. En el punto 6 se mencionaban las labores mal hechas, lo que se achacaba a la falta de sujeción al trabajo. Por primera vez, en el punto 24, se daba una duración concreta para el aprendizaje, que debía ser de cinco años, y se introducía una innovación en el examen, pues la pieza a ejecutar por el solicitante la haría en el taller de su maestro y este certificaría que era obra de su aspirante. El fiscal achacó a esta proposición el que no se recurriese a los premios, mencionando la política educativa de la Real Sociedad Económica Matritense, que se había fundado en 1775 .

38 BAENA, José y VIVES MEJÍA, Gustavo: Santa Fe de Antioquia-breve monografía-, Santa Fe de Antioquia, Museo Juan del Corral, 2002, s/p.

39 ALMARZA VILLALOBOS, Ángel y MARTÍNEZ GARNICA, Armando (eds.): Instrucciones para los diputados del Nuevo Reino de Granada y Venezuela ante la Junta Central Gubernativa de España y las Indias, Bucaramanga, Universidad Industrial de Santander, 2007.

40 ARCHIVO CENTRAL DEL CAUCA (ACC) Independencia, 16 mayo-4 junio de 1819.

41 LOAIZA CANO, Gilberto: "Cultura política popular y espiritismo (Colombia, siglo XIX)", Historia y Espacio, n' 22 (2009), pp. 3-4.

42 Correo curioso, erudito y mercantil de la ciudad de Santafé de Bogotá $\mathrm{n}^{\circ} 12$ (5 de mayo de 1801).

43 STEUART, James: Bogota in 1836-7, Nueva York, Harper \& Brothers, 1838, pp. 141 y ss.

44 Este documento ha sido trascrito por VARGAS MURCIA, Liliana, en el proyecto presentado en 2010 al Instituto Colombiano de Antropología e Historia, con el título Búsqueda y análisis de fuentes de archivo para el estudio del arte de la pintura en la Nueva Granada a principios del siglo XIX, pp. 119-123. 
En estos vaivenes de la reactivación gremial, las Cortes de Cádiz abolieron esas corporaciones el 13 de septiembre de 1813, ratificando la libertad de trabajo y de instalación de espacios para la producción. Aquel decreto volvería a ser anulado tras la llegada de Fernando VII, el 9 de junio de 1815. Sin embargo, tanto la abolición como la reinstauración afectaron ya poco a la Nueva Granada, implicada por entonces en los procesos de su independencia, en el que muchos artesanos tuvieron una participación muy activa, que les favoreció su pervivencia e incluso lograron demostrar su fuerza en la nueva nación. Es más, los gremios, prohibidos en el artículo 195 de la Constitución del Estado de la Nueva Granada, de 1832, en función de la libertad de ingenio, enseñanza e industria, en algunos lugares se convirtieron en una fuerza política, en la medida en que ayudaron en las luchas independentistas y entrarían con fuerza en la nueva situación, hasta el punto de marcar su desarrollo político y consiguiendo poner freno a los intentos de libre cambio que afectaron a otras naciones y que en Colombia lograron detenerse, en buena medida, hasta la época de la presidencia del payanés Tomás Cipriano de Mosquera (1845-1849).

\section{LOS CENTROS DE ENSEÑANZAS DE OFICIOS}

La alternativa o la complementación al sistema gremial en cuanto a los aspectos de enseñanza fue la creación de centros de aprendizaje. Estos, en realidad, presentaban algunas variaciones, pero se vieron como una posibilidad de desarrollo para un artesanado carente de toda formación y viviendo a veces casi en la indigencia. Es más, muchos estuvieron vinculados a la beneficencia, pues la necesidad de gentes útiles, que defendían los ilustrados, convertía a los lugares de acogida de pobres y vagabundos en espacios idóneos para un reciclaje humano en lo laboral, que permitiese solucionar al mismo tiempo un problema social y otro económico, dejando atrás una concepción meramente religiosa de la caridad. El virrey Messía de la Cerda pensó en casas de pobres y vagabundos, donde se enseñasen oficios, tarea que afrontaría posteriormente el virrey Guirior, después de que el monarca aprobase la fundación de dos de aquellas casas en Santafé, en 1774, y se le diesen, a proposición de Moreno y Escandón las Constituciones de las Reales Casas de Hospicios de Santa Fe, aprobadas por cedula de 10 de junio de 1777. En ellas se especificaba que a los vagos y ociosos se les examinaba su aptitud para dedicarlos al trabajo, amén de instruir a los niños huérfanos y abandonados en algún arte con el que poder subsistir y hacerse provechosos a la república ${ }^{45}$. Ese mismo año José de Gálvez había mandado entregar el hospicio de San Felipe Neri a los capuchinos, entre los que estuvo, desde 1778, Joaquín de Finestrad, unos de los grandes promotores de reformas; las obras se iniciaron y la iglesia fue consagrada en 1781 por el obispo Compañón, siendo regentado por aquellos frailes hasta $1819^{46}$. En 1789 Francisco Silvestre proponía la creación de hospicios y casas de corrección en las cabezas de provincia y poblaciones importantes "para hacer aplicados a los que no lo son" ${ }^{47}$. José Manuel de Ezpeleta quiso utilizar el hospicio de

45 Recogidas en la obra de RAMÍREZ, María Imelda: De la caridad barroca a la caridad ilustrada. Mujeres, género y pobreza en la sociedad de Santa Fe de Bogotá, siglos XVII y XVIII, Bogotá, Universidad Nacional de Colombia, 2006, pp. 281-292.

46 IBÁÑEZ, Pedro María: Crónicas de Bogota II, Bogotá, Imprenta de la Luz, 1891, c. XXX

47 SILVESTRE, Francisco: "La jurisdicción de la Real Audiencia de Santa Fe", en Francisco Javier Vergara y Velasco: Nueva Geografía de Colombia escrita por regiones naturales T. III, Bogotá, Banco de la República, 1974 , p. 1179. 
Bogotá para enseñar varios oficios, de acuerdo con una idea que ya había estado en la mente del virrey Flórez, en 1788; pues de allí debían salir maestros, sobre todo, de los que no había en la tierra. Como consecuencia se mandó construir un nuevo edificio, equipado con máquinas de tejer que se llevaron de Europa, lo que permitió calificar aquel centro como "el más precioso monumento de la Caridad Ilustrada"48. Aquel deseo de formación en los centros de beneficencia se reactivaría de nuevo con el virrey Pedro Mendinueta, que, en 1803, promocionaba la fabricación textil en las casas y hospicios de caridad, con el fin de que produjesen para su propio autoconsumo y el excedente se pudiese vender ${ }^{49}$.

La enseñanza "reglada" de los oficios, estuvo siempre en la mente de los neogranadinos ilustrados. Además se ofrecía la ventaja de que, salvo casos muy especiales y casi siempre relacionados con la beneficencia, este tipo de formación no estaba controlado por la Iglesia, por lo que no chocaba con los intereses de las órdenes religiosas, siempre vigilantes de lo que consideraban sus derechos y tradiciones.

Quien mejor representó aquel interés fue, sin duda, Francisco José de Caldas, gran defensor de la vinculación entre educación y progreso, que animaba a los ricos de Santafé a crear escuelas, como la de las Nieves, fundada por el que fuera alcalde de campo, Santiago Umaña, en la que abundaban los libros de ciencias y artes ${ }^{50}$ y cuyas ordenanzas las daría el cabildo bogotano en $1809^{51}$. El que Caldas elogiase este modelo respondía a que se habían seguido en buena medida las pautas que él mismo había elaborado para las sociedades patrióticas y que le hicieron soñar con lugares ideales en su tierra: "Entro en las ciudades populares: el gusto de la arquitectura se ha introducido en ellas; por todas partes encuentro fábricas, copiosas manufacturas, y todas las producciones de las artes" ${ }^{2}$.

De especial relevancia en este sentido fue la villa de Mompox, donde, gracias al comerciante Pedro Martínez Pinillos y su esposa ${ }^{53}$, se fundó el Colegio de San Pedro, en 1806, en el que el clérigo Eloy Valenzuela, primer director, puso también énfasis en la educación técnica frente a la teórica y que debía darse a todo tipo de gentes, aunque en la asistencia a las clases, los alumnos, de acuerdo con su condición, se sentarían en bancos distintos, porque según el promotor, todavía faltaba ilustración. El colegio tenía todos los visos de lo que debía ser la modernidad, pues amén de las enseñanzas útiles, como era el que los alumnos aprendieran a ejecutar instrumentos de trabajo, se tenían también como fines el que estos realizaran viajes por Europa para entrar en contacto con lo más avanzado de la ciencia y la técnica en aquellos momentos ${ }^{54}$.

En todo este panorama surgía como fundamental una materia para el aprendizaje de los oficios: el dibujo. Su enseñanza, junto con la de las matemáticas y la química fue una obsesión de muchos ilustrados, con el fin de acercar al mundo de la ciencia y el desarrollo a sus propios conciudadanos. En la Instrucción se recordaba lo que

48 Papel periódico de la ciudad de Santa fe de Bogotá, nº 50 (27 de enero de 1792).

49 COLMENARES, Germán: Relaciones e informes de los gobernantes de la Nueva Granada III, Bogotá, Banco Popular, 1989, p. 76.

50 CALDAS, Francisco José de: Semanario de la Nueva Granada. Miscelánea de ciencias, literatura, artes e industria, París, Librería Castellana, 1849, p. 58.

51 HERNÁNDEZ ALBA, Guillermo, Documentos para la Historia de la Educación en Colombia VI, Bogotá, Kelly, 1985, pp. 245-258.

52 CALDAS, op. cit., p. 216.

53 AGI, Santa Fe 1020.

54 URBINA OSPINO, Gonzalo: "Las huellas pedagógicas de don Eloy Valenzuela Mantilla en el devenir histórico-educativo del Colegio de Pinillos de Mompox" (en prensa.) 
Campomanes había propuesto para España; es decir, que en cada capital se creasen cátedras de matemáticas, aritmética, geometría y álgebra, para enseñar los principios de cada arte, así como otra cátedra de maquinaria para aplicar los progresos técnicos y perfeccionar los instrumentos ${ }^{55}$. Mutis en su plan para la cátedra de Matemáticas del Colegio del Rosario, en 1787, recordaba que a ellas se debía el adelantamiento o atraso del arte, la industria, etc. de las naciones civilizadas ${ }^{56}$. Pero en Nueva Granada no tardó en verse la imposibilidad de la enseñanza de las matemáticas a los artesanos, habida cuenta de su escasa formación, pero, por el contrario, se insistió en el dibujo. Lo cierto es que este interés estaba en función de la necesidad de renovación científica, del que estas tierras fueron un gran exponente, aunque no se llegará a fundar una escuela de Bellas Artes para impartir esa materia, a pesar de los intentos que hubo hacia 1801, cuando se abogaba por su creación en Bogotá "para que logremos tener consumados profesores" ${ }^{57}$.

En Bogotá funcionó una escuela gratuita de dibujo, fundada por Mutis en 1783; aunque en principio fue para formar a miembros de la expedición botánica, muchos siguieron ejerciendo después el arte de la pintura y su primer director sería el íntimo colaborador de Mutis, Salvador Rizo ${ }^{58}$. La de Mariquita, sería fundada por Mutis y Salvador Rizo, aunque también en función de la formación de pintores para la mencionada expedición. El payanés José Ignacio de Pombo, amigo de Mutis, consiguió que el Consulado de Cartagena fundase una de esas escuelas, tras su proposición de 1810, que ampliaba también a Mompox y Corozal $^{59}$. Ese mismo año se abría una escuela de dibujo y arquitectura en Santafé por Bernardo Anillo, discípulo del ingeniero y matemático Benito Bails ${ }^{60}$, aunque parece que tuvo poco éxito y apenas hay menciones de ella ${ }^{61}$. El interés era tal en este sentido, que el título XI art. 2 de la Constitución de Cundinamarca, de 1811, establecía que en todos los pueblos debía haber escuelas de primeras letras y dibujo.

Para el desarrollo de la enseñanza de los oficios en España y América fueron fundamentales en el siglo XVIII las sociedades económicas, sobre todo en el último cuarto de la centuria. El Correo curioso decía que "el establecimiento de una sociedad patriótica

55 RODRÍGUEZ DE CAMPOMANES, Pedro, Discurso sobre la educación popular..., pp. 38-39. 78-79. FAJARDO DE RUEDA, Marta, op. cit., p. 191. MAYOR MORA, Alberto: Cabezas duras y dedos inteligentes. Estilo de vida y cultura técnica de los artesanos colombianos del siglo XIX, Bogotá, Instituto de Cultura Colombiana, 1997, pp. 26-27.

56 Plan reproducido en Diana Soto Arango, Mutis. Educador de la élite neogranadina, Tunja, Búhos, 2005, pp.203-207.

57 CORTÉS, Severo: "Lo que falta y sobra en el Nuevo Reino de Granada", Correo Curioso de Santafé de Bogotá $\mathrm{N}^{\circ} 18$ (16 de junio de 1801), pp. 69-72.

58 Sobre los pintores de esta expedición puede verse GONZÁLEZ, Beatriz y AMAYA, José Antonio: "Aprendices y alumnos de la expedición botánica", Revista Credencial Historia, no 74 (1996).

59 SILVA, Renán: Los ilustrados de Nueva Granada 1760-1808. Genealogía de una comunidad de interpretación, Bogotá, Banco de la República, 2002, p. 135. MÚNERA, Alfonso: "José Ignacio Pombo: poblador de las tinieblas, en Diana Soto Arango (y otros): Científicos, criollos e ilustración, Madrid, Doce Calles, 1999, p. 116. Sergio PAOLO SOLANO: "El mundo del trabajo urbano en el Caribe colombiano durante el siglo XIX”, en José Polo y Sergio Paolo Solano (eds.), Historia social del Caribe colombiano, Medellín, La Carreta, 2011, p. 79.

60 Fue autor de la obra publicada en Madrid por Ibarra, en 1775, Elementos de Matemáticas; y en el mismo lugar, en 1776, de los Principios de matemática donde se enseña la especulativa, con su aplicación a la dinámica, hydrodinámica, óptica, astronomía, geografía, gnomónica, arquitectura, perspectiva, y al calendario. 61 SILVA, op. cit., p. 461. 
debe mirarse como uno de los primeros anuncios de felicidad del Reyno"62. Sin duda, representaban mejor que ninguna otra institución esa relación entre el mantenimiento de los gremios, la potenciación de la industria y la libertad de trabajo. La mencionada Constitución de Cundinamarca establecía la necesidad de su creación para promover, entre otras cosas, la industria, artes, oficios y fábricas, aunque era evidente que en la fundación de muchas de ellas prevalecían las ideas fisiócratas, en que la industria y el comercio eran complementos necesarios de la agricultura.

Los primeros intentos sin resultado de crear una de estas sociedades en la Nueva Granada se deben al virrey Solís y posteriormente a Flórez. La primera que se fundó, sin embargo, estuvo en Mompox, desde 1784, bajo la dirección de Gonzalo José de Hoyos, cuyo objetivo principal era el fomento del cultivo de algodón. En 1791, Manuel del Socorro Rodríguez, que había llegado desde la Habana en 1789, y que ejerció en la ciudad de Santafé como bibliotecario, y admirador de Carlos III, José de Gálvez y Godoy, al que dedicó odas y elogios ${ }^{63}$, planteó también la creación de una Sociedad Económica para fomentar la industria y las artes. Pero sería Pedro Fermín de Vargas, quien con más interés abogase por estas sociedades, en $1789^{64}$, sobre lo que volvió a insistir en 1801, considerando que era necesario que los jóvenes viajasen para instruirse ocultamente en máquinas, especialmente a Inglaterra, Francia y sus colonias. La idea de sus fundaciones se extendía, además de a Bogotá, a Cartagena, Popayán, Quito y Caracas, considerando que con los fondos que generase se importaría maquinaria para la agricultura y la industria. Al mismo tiempo, en 1801, Caldas estaba elaborando un proyecto de sociedad patriótica en Popayán ${ }^{65}$.

La de Bogotá comenzaría su funcionamiento en 1801, gracias a los desvelos de Jorge Tadeo Lozano, quien manifestaba su necesidad "para que no caminen los artífices tan a tientas como hasta ahora; lo que unido a la enseñanza del dibujo y de otras artes evitaría el aumento de los ociosos, pues mas vil es el noble que pasa sus días en una vergonzosa pereza que el artesano que profesa un oficio, por más humilde que sea”. Sus objetivos eran en primer lugar la agricultura, la cría de ganados y los oficios, por lo enlazadas que estaban entre sí estas actividades ${ }^{66}$. En 1811 se fundaba la de Cartagena después de haberse intentado desde la década de los ochenta del siglo XVIII. En realidad todas fueron un fracaso, pues hasta la de Mompox, como pionera, no acabo por obtener el placet, como tampoco la de la capital.

\section{LA FORMACIÓN PARA EL DESARROLLO "INDUSTRIAL"}

Si la renovación de los gremios había tenido el problema de no poder contar con muchos artífices de buena formación, la situación aún era peor para ponerse al día en el desarrollo fabril de la Nueva Granada y su posibilidad de competir con las importaciones. El virrey Pedro Messía de la Cerda advertía, en 1772, que allí había pocas manufacturas y orientadas al autoconsumo, existiendo una gran apetencia de productos

62 Correo Curioso, $\mathrm{n}^{\mathrm{o}} 39$ (10 de noviembre de 1801).

63 AGI, MP-Pasquines 2 y 3 y Estado 53, n. 84.

64 VARGAS, Pedro Fermín de: Pensamientos políticos sobre la agricultura, comercio y minas del virreinato de Santafé de Bogota, 1986, pp. 29-30.

65 PACHECO, Juan Manuel: La Ilustración en el Nuevo Reino, Caracas, Universidad Andrés Bello, 1975, pp. 73-75.

66 Correo Curioso, $\mathrm{n}^{\circ} 39$ (10 de noviembre de 1801). 
extranjeros, que acabarían hundiendo las propias, como había sucedido con las quiteñas, a causa de los registros sueltos que entraban por el cabo de Hornos ${ }^{67}$. La competencia de las manufacturas fabriles, que dieron al traste con muchas pseudoindustrias, como las mencionadas de Quito, también despertó los deseos de un nuevo tipo de formación de la población para adecuarla a los nuevos tiempos. Pero la producción fabril implicaba una mayor división del trabajo, mayor especialización y una mano de obra asalariada, situación para la que la América española no parecía estar muy preparada. Curiosamente, las posesiones hispánicas habían sido pioneras en el siglo XVI de ese tipo de producción, especialmente en los obrajes, batanes, tejares, astilleros, trapiches, etc. Sin embargo, fueron incapaces de adaptarse a los tiempos y modernizarse, quedándose como algo obsoleto y anquilosado en el tiempo, amén de que cualquier producción fabril no dependía de las autoridades neogranadinas sino que debía contar con la aprobación real.

El peligro llegó, sobre todo, con el Reglamento de Comercio Libre de 1778, que daría lugar a que el artesanado viera como sus productos no podían competir ni siquiera en los mercados internos. Los nuevos tiempos que corrían para el desarrollo económico exigían otro tipo de formación para familiarizase con la nueva maquinaria y materias primas, así como otro tipo de organización del trabajo. Aquello era casi imposible que lo pudiera abordar un taller artesanal, por mucho que se hubiese adaptado a los nuevos tiempos y que, incluso, como solicitaba Díaz de Hoyos en el Reglamento de los gremios de la plebe, se imitasen las obras europeas.

Las autoridades metropolitanas habían llegado a la conclusión de que América debía ser una despensa de materias primas y no un lugar de desarrollo competitivo con las manufacturas peninsulares. Ejemplos no nos faltan en Nueva Granada, pero valga el del arzobispo Caballero y Góngora, del que se decía, que a sus súbditos neogranadinos les hizo ver el beneficio ventajoso de las manufacturas y establecimientos fabriles ${ }^{68}$; aunque en realidad su pensamiento estaba en que esto era prioritario para España. Igualmente Francisco Silvestre tenía claro que la Nueva Granada debía mantener su dependencia económica de España, generando una necesidad de manufacturas, incluso llegó a proponer el cierre de la fábrica de tabaco de Bogotá, si debía subsistir la de Sevilla, y, por lo tanto, la producción de tabaco de San Juan de Girón debía tener como destino la fábrica hispalense ${ }^{69}$.

Amén de lo anterior, sobre todo los entre los ilustrados criollos, se pensó en dos soluciones para la formación de los trabajadores en los modos de producción fabril: enviar jóvenes a Europa que se familiarizasen con las nuevas formas de producción, como lo planteó el colegio de San Pedro de Mompox; o contar con extranjeros que llegasen para formar a los neogranadinos en las nuevas técnicas y formas de organización laboral.

La presencia de extranjeros pocas veces dio buenos resultados, pues quienes llegaban a ejercer un oficio o a abrir un establecimiento, lo hacían de forma temporal y sin desvelar los secretos de su arte, amén de inmiscuirse en los oficios, en detrimento de los

67 GIRALDO JARAMILLO, op. cit., p. 60.

68 TOLEDANO, Francisco de Paula: Oración panegírica e historial en justa memoria del Excmo. e Ilmo. Señor Don Antonio Caballero y Góngora, Granada, Herederas, 1798, p. 41.

69 SILVESTRE, Francisco: Descripción del reino de Santa fe de Bogotá, Bogotá, Epígrafe, 1927, pp. 32 y 46. 
vecinos, como ya se acusaba en Cali a principios de la centuria ${ }^{70}$. Un buen ejemplo de aquel fracaso fue el de los alemanes que acudieron con Juan José Elhúyar a las minas ${ }^{71}$, al que Mutis denominaría "una esperanza de la industria en el Nuevo Reino"72. Lo cierto es que en muchos lugares, y sobre todo entre las autoridades criollas, se gestó una cierta confianza en el desarrollo de los oficios y de la actividad fabril por los europeos y norteamericanos, por su mejor formación, y con la confianza de que podían transmitir sus conocimientos, supuestamente más evolucionados, al artesanado autóctono. Así, en Antioquia, ya se había pensado en la llegada de soldados católicos centroeuropeos, que además supiesen oficios ${ }^{73}$. Aquella presencia foránea a lo largo del siglo en el territorio neogranadino dio lugar a un registro, en 1791, en que se ponían como condiciones la catolicidad, la fidelidad al rey y la renuncia a todo fuero de extranjería y de dependencia de su lugar de origen. Por tanto, solo podrían ejercer actividades mecánicas los avecindados, mientras que los transeúntes, si querían hacerlo, disponían de dos meses para naturalizarse. Pero la abolición del corporativismo gremial por las Cortes de Cádiz permitiría igualmente a los foráneos establecer fábricas y talleres y ejercer cualquier oficio sin necesidad de examen, título o incorporación a un gremio.

Frente a todos los contratiempos algunos teóricos no cejaron en su empeño de estimular la producción fabril en la Nueva Granada. Buen ejemplo de ello nos lo presenta el plan de estudios de la Universidad, en tiempos de Caballero y Góngora, donde se decía que las máquinas y las artes industriales eran objetos agradables que excitaban la curiosidad, aplicación y emulación de los jóvenes ${ }^{74}$. Es más, en el mismo plan, al mencionar la cátedra de Matemáticas y las enseñanzas de Química, establecían que el docente pusiese especial atención en todo en lo referente a la industria y el comercio, como la mecánica, arquitectura, hidráulica, etc. ${ }^{75}$.

Lo cierto es que los atisbos de producción fabril no fueron exitosos en Nueva Granada. Ni siquiera en la producción textil, más preparada para este cambio en sus obrajes de Socorro, Pasto, Boyacá y Cundinamarca, pues precisamente la producción de paños en todo el mundo fue la más afectada por la revolución industrial inglesa. A pesar de todo lo anterior, no faltaron intentos de promoción, como la fábrica que desde 1695 habían regentado los jesuitas en Cartagena ${ }^{76}$. El virrey Pedro Messia de la Cerda (1761-1772) había llevado loceros desde España para que enseñasen el arte de la loza vidriada, creando una fábrica para vasijas con las que transportar pólvora, que perduró hasta casi la independencia ${ }^{77}$, y que nos recuerda su retrato del Museo de Arte Colonial.

\footnotetext{
70 ARBOLEDA, Gustavo: Historia de Cali desde los orígenes de la ciudad hasta la expiración del periodo colonial, Cali, Imprenta Arboleda, 1928, pp. 172 y 249.

71 CAYCEDO, Bernardo J.: D'Elhúyar y el siglo XVIII neogranadino, Bogotá, Ed. de la Revista Jiménez de Quesada, 1971, pp. 171-175. GÄRTNER, Álvaro: Los místeres de la minas: crónicas de la colonia europea más grande de Colombia en el siglo XIX, surgida alrededor de las minas de Marmato, Supia y Rioscuro, Manizales, Universidad de Caldas, 2005, pp. 102-104.

72 CAYCEDO, Bernardo J.: op. cit., p. 139.

73 SILVESTRE, Francisco: Relación de la provincia de Antioquia, Medellín, Secretaría de Educación y Cultura, 1988, p. 471.

74 HERNÁNDEZ DE ALBA, Guillermo: op. cit., p. 306.

75 Ibídem, pp. 312-313.

76 FANDINO MERZ, Martha: Producción de loza en Cartagena de Indias 1650-1770. Un análisis de la cultura materia. Tesis de la Universidad de los Andes (2000), pp. 26-27.

77 GROOT: op. cit., p. 135. OSPINA VÁZQUEZ, Luis: Industria y protección en Colombia 1810-1930, Medellín, Santa Fe, 1955, p. 102.
} 
Mon y Velarde intentó crear una fábrica de lienzos en Santa Fe de Antioquia. Pedro Fermín de Vargas había propuesto la creación de una fábrica de papel basto. Francisco Silvestre recomendaba no crear fábricas de textiles finos y planteó una fábrica de lonas en Santa Marta o Cartagena para abastecer a las escuadras ${ }^{78}$. En esta última ciudad, en 1810, José Ignacio Pombo y el propio Consulado cartagenero intentaban favorecer la creación de una fábrica de vidrio. Pero muchos de aquellos proyectos no llegaban a buen término, como se denunciaba con ejemplos como el del batán bogotano de Juan de Illanes, fracasado por culpa del gobierno; o los impedimentos para el funcionamiento de la fábrica de loza de mesa de Chavarría; o las mil trabas que tuvo Pierri para fundar una fábrica de sombreros ${ }^{79}$. Desconocemos también el futuro de la producción de papel en Bogotá, a partir de 1811, cuando el agustino Diego Padilla informaba que Juan Bautista Estévez había fundado una fábrica de ese producto ${ }^{80}$.

Los productos estancados eran los que tenían una condición más fabril y con una mayor especialización de sus trabajadores, asalariados, en los diferentes procesos. Pero tales estancos no gozaban de la simpatía popular, como quedó probado en la Revolución de los Comuneros (1781), en que la ira de la plebe se puso de manifiesto, especialmente, ante los estancos de aguardiente y tabaco. Además tales productos eran los más afectados por la competencia de los pequeños productores y del contrabando. Las fábricas de aguardientes existían en Medellín, Honda, Mompox, Cartagena, Santa Marta y Corozal.

En esos centros de control estatal el aprendizaje se hacía internamente o se externalizaba el trabajo, aunque con frecuencia los ejercitantes de oficios de más responsabilidad llegaban formados desde la Península u otros lugares. Fue allí donde los trabajadores se familiarizaron más con las nuevas tecnologías, como sucedió con las fábricas de moneda, que en Nueva Granada se encontraban en Popayán y Santafé. O como sucedió con la fábrica de pólvora de Bogotá, que acabó cerrando sus puertas, en 1789, por expreso deseo del virrey Gil y Lemos, alegando su improductividad, aunque la orden de extinción era del año anterior, para favorecer a la existente en Latacunga ${ }^{81}$. En otros casos, como en el de la fábrica de salitres de Sogamoso se estaba intentando su reforma en $1783^{82}$.

Lo cierto es que la producción fabril no acaba de encontrar eco en estos territorios ni era capaz de poder competir en su propio mercado, por lo que en el informe de 1810 de José Ignacio Pombo, se solicitaban estímulos fiscales para quienes estableciesen fábricas, incluso pidió perfeccionar el trabajo en aquello que se prestara a la producción industrial, como la talabartería y la jabonería, en los que veía imprescindible la aplicación de los nuevos métodos de la química aplicada ${ }^{83}$. Precisamente la aplicación de esta ciencia al desarrollo productivo fue muy tenida en cuenta por casi todos los autores de reformas educativas en la época; y así, en el plan de Eloy Valenzuela para el

\footnotetext{
78 SILVESTRE, Francisco: Descripción del reino de Santa fe..., pp. 31 y 47.

79 Escrito de GUTIÉRREZ, Frutos Joaquín, de 25 de septiembre de 1810, recogido en Proceso histórico del 20 de Julio de 1810, Bogotá, Banco de la República, p. 246.

80 PADILLA, Diego: Aviso al público 17. Sábado 19 de enero de 1811. (existe edición actual de Javier Campos y Fernández de Sevilla, realizada por el Instituto Escurialense de Investigaciones, 2011).

81 AGI, Quito 246, N. 8.

82 AGI, Indiferente 1737.

83 SOLANO, Sergio Paolo: op. cit., pp. 78-79.
} 
Colegio-Universidad de Mompox se la definía como "un tesoro inagotable de inventos y secretos para todas las artes" $"$. El propio Mutis, en el plan sobre esta asignatura para el Colegio del Rosario, en 1801, decía que, al igual las matemáticas, era una ciencia general que difundía sus luces por todas las ciencias y artes, necesaria para los jóvenes que querían promover algún ramo de la felicidad pública ${ }^{85}$. Pero casi siempre los estudios de química y matemáticas se iban relegando por la falta de especialistas.

El fracaso de este tipo de producción fabril, debido en buena medida a la falta de formación, amén de las trabas metropolitanas, fue patente y todavía la ley de 15 de mayo de 1848, se trataba de solucionar ese viejo problema, con evidentes ventajas para quien lo pusiese en práctica, manifestando que todo extranjero o neogranadino que inventase alguna máquina o métodos de aplicación a la industria se le daría una patente de cinco a veinte años para fabricar y vender lo que fuese producto de su invención.

\section{CONCLUSIONES}

Desde el último cuarto del siglo XVIII hasta la independencia se observa en Nueva Granada una clara tendencia al reformismo educativo en todos los ámbitos, que se prolongó tras la independencia, y, entre ellos, como no podía ser menos, en el de los oficios mecánicos, en la medida que se querían modernizar con varios fines, amén de solucionar el autoabastecimiento para poder competir con los productos extranjeros, que comenzaban a invadir aquellos territorios. Poder competir con los productos europeos, fueran de la metrópoli o de otras potencias, pasaba por un proceso de formación del artesano, que no tuvo demasiado éxito, a pesar de la reforma gremial y de la creación de centros, en que se adecuaran las nuevas enseñanzas aplicadas a la producción manufacturera. No hubo, sin embargo, una relación entre los esfuerzos de los ilustrados y los resultados, habida cuenta de varios siglos de desorganización y con una sociedad no demasiado proclive a aceptar ciegamente las propuestas de una minoría de intelectuales y políticos, amén de una metrópoli que veía sus posesiones en función de un mercado consumidor, lo que ahogaría buena parte de los primeros intentos de industrialización.

Las propias características y el escaso desarrollo artesanal sirvieron para no poner en entredicho el sistema gremial, como estaba sucediendo en muchos lugares de Europa, aunque se plantearon profundas reformas en el mismo, en función del control que la Corona quiso tener sobre todo tipo de asociaciones y que en aquellas tierras quedaría reflejado en la Instrucción para los gremios. Esta, parece que no consiguió sus propósitos, puesto que las ciudades neogranadinas siguieron siendo un ejemplo de descontrol y de falta de calidad en sus productos; aunque, eso sí, muchas que habían vivido en una total desorganización gremial pasarían ahora a tener sus gremios y, supuestamente, un control de la formación del artesano, que muchas veces fue solamente teórico. A aquel retraso en la enseñanza de los oficios, a pesar de los intentos realizados, contribuyó la propia situación política que se vivió en las décadas postreras de pertenencia a la corona española y a la carencia de unos efectivos humanos que, como formadores, permitiesen

84 SOTO ARANGO, Diana: "Las constituciones del Colegio Universidad de Mompox: un modelo para la enseñanza ilustrada", Revista de la Academia Colombiana de Ciencias, no 78 (1996), p. 536.

85 Plan reproducido en SOTO ARANGO, Diana: Mutis. Educador de la élite neogranadina, Tunja, Búhos, 2005, pp. 279-280. 
llevar a cabo tales cambios. Pero parece que el artesanado sí adquirió una cierta conciencia de su poder social, sobre todo cuando apreciamos lo que sucedería en los treinta años posteriores a la independencia.

Los reformadores, empeñados en revitalizar conceptos como el de virtud, laboriosidad, higiene, calidad, etc., es decir, una formación integral del hombre, no escatimaban esfuerzos por aquel desarrollo, tanto en lo gremial, como en otras enseñanzas de beneficencia e, incluso, en los pocos exitosos intentos por crear sociedades económicas. Fueron muchas las voces de los ilustrados neogranadinos que se levantaron en favor de aquellas reformas educativas en función de un desarrollo de la propia tierra y como solución a unos problemas que asolaban a la Nueva Granada, estableciendo una relación ociosidad-delincuencia, que impedía aquel pretendido desarrollo y que solo por la formación podría salvarse. Formación que para favorecer la calidad del artesano incluía el aprendizaje de otras materias, especialmente el dibujo, amén de las elementales lectura y escritura.

En la época predominaban las ideas fisiocráticas, lo que hizo que el mundo de los oficios se viese supeditado al desarrollo de la agricultura, postura defendida además por los ilustrados españoles en la medida que veían sus posesiones americana como meras productoras de materias primas; por lo que las reformas artesanales iban muy vinculadas al consumo interno, sin poner en peligro las importaciones europeas, de ahí la escasez de centros de producción fabril, lo que se convertiría casi en una obsesión tras el fin del dominio español.

Queda claro además, que a pesar de tratar de promocionar los trabajos mecánicos en todos los sectores sociales y elevar la categoría de quien practicaba tales oficios, la sociedad neogranadina, como otras, no estaba preparada para ello y, a pesar de los esfuerzos su ejecución siguió dependiendo de sectores poco o nada privilegiados en la sociedad, especialmente en la media en que la formación, en función de la utilidad, se extendió a vagabundos, huérfanos, presos, etc. Todo ello ratificó las desigualdades sociales propias del Antiguo Régimen.

Si podemos decir que casi todos los aspectos formativos de los ilustrados neogranadinos en lo referente al mundo de los oficios habían fracasado, también es cierto que se generó una cierta mentalidad reformista que tendería a dar sus frutos en las décadas posteriores, aunque también quedaría ahogada por el desarrollo del librecambismo. 